\title{
Shame-based appeals in a tobacco control public health campaign: potential harms and benefits
}

\author{
Cati G Brown-Johnson, Judith J Prochaska
}

Smoking is the leading preventable cause of death worldwide, responsible for 1 in 10 deaths globally ( $>5$ million a year). Tobacco use adversely impacts not just smokers, but also those around them through secondhand smoke exposure. Given the significant personal and societal costs of tobacco use, any strategy to reduce smoking should be considered.

In this issue, Amonini et al ${ }^{1}$ report on development and evaluation of a shamebased public health campaign in Perth, Australia. Public health media campaigns in Australia, in particular, have raised awareness and instigated behaviour change via approaches ranging from direct and forceful (eg, 'Belt Up or Suffer the Pain' seatbelt campaign ${ }^{2}$ ) to humorous and memorable (eg, 'Slip! Slop! Slap!' for skin cancer prevention ${ }^{3}$ ).

In developing their tobacco control ad campaign, Amonini et al conducted focus groups with smokers and interviewed former smokers, identifying salient themes of social isolation (eg, "you feel like a 'leper'”). Next, they created and piloted an ad prototype in an experimental setting, which demonstrated believability/relevance and perceived efficacy in stopping smokers from smoking. Finally, they created the shame-based ad, evaluating it in a publicly launched campaign where a majority of respondents self-reported in the first several weeks that they reduced cigarette consumption $(36 \%)$, attempted cessation $(16 \%)$ or quit $(2 \%)$.

While suggestive as a promising public health approach, the potential for harm associated with an emphasis on shame also bears consideration, particularly when in relation to a behaviour sustained through addiction and increasingly concentrated among marginalised groups. Today, smokers in Australia and other industrialised countries are largely characterised by lower income and education,

Department of Medicine, Stanford Prevention Research Center, Stanford University, Stanford, California, USA

Correspondence to Dr Judith J Prochaska,

Department of Medicine, Stanford Prevention Research Center, Stanford University, Medical School Office Building, X316, 1265 Welch Road, Stanford, CA 94305-5411, USA; JPro@stanford.edu ethnic minority status and co-occurring mental and physical health disorders. ${ }^{4}$ Capitalisation on shame-based public health campaigns will, in effect, target these groups.

In contrast, the tobacco industry's campaigns have emphasised themes of freedom, affluence and excitement, creating the perception that smoking is a choice of free will. ${ }^{5}$ In this context, when smokers fail to quit, they often blame themselves. ${ }^{6}$

\section{SMOKING-RELATED SHAME AND STIGMA}

Stigma is a concept derived from classic sociology, whereby negative differential treatment is experienced by groups with socially 'discredited' identities. ${ }^{7}$ Stigma related to smoking is experienced as shame, self-judgement and outright discrimination in the form of denial of goods, opportunities and services. ${ }^{8}$ Shame is a central focus of research on lung cancer stigma (where smokers blame themselves for the disease), ${ }^{9}$ and an emergent area of interest with respect to tobacco use more generally. ${ }^{10}$

Research indicates about $40 \%$ of smokers and ex-smokers perceive substantial smoking stigma, ${ }^{11}$ with a 'deep divide' existing between smokers and nonsmokers. ${ }^{12}$ While a minority of smokers report experiencing outright discrimination (eg, denial of work or housing), smokers may withstand many tiny insults (eg, purposeful coughing in their presence, glaring looks from non-smokers). ${ }^{12}$ Smokers speak of 'smoking islands', the few remaining areas, largely isolated, where one can smoke without judgment. ${ }^{13}$ While cessation is a positive possible response to smoking stigma, of concern is smokers' reported hiding of their use from potential supports, such as family, friends and healthcare providers. ${ }^{11}$

Shame-based antitobacco public health campaigns may lead smokers to attempt cessation in isolation, unassisted. Only $3-5 \%$ of unaided quit attempts are successful, and defeated efforts may negatively impact smokers by decreasing self-efficacy and increasing stigmatisation on relapse. To counteract this potential, shame-based appeals ought to at minimum include explicit instructions to contact a clinician or quit-line for help with quitting smoking.

\section{RISKS OF A SHAME-BASED} ANTITOBACCO MEDIA APPROACH

As with medications, side effects must be considered in terms of likelihood as well as magnitude. Of concern, in their threepart study Amonini et al did not test for increases in experienced shame among viewers.

Prior to dissemination, assessment of message impact on shame and stigma should be examined, particularly among disadvantaged groups. Broad-based communication interventions will reach those diagnosed with lung cancer and chronic obstructive pulmonary disease, who, smoker or not, may internalise the stigma of negative societal impressions. Lung cancer stigma is associated with poorer psychosocial outcomes ${ }^{14}$ and morbidity ${ }^{15}$ among smokers and non-smokers equally. ${ }^{16}$ As such, shame-based public messages may contribute to stress and increased symptom burden. With regard to smokers with mental illness, imagery suggestive of individuals as lepers or isolates may compound stereotypes with adverse effects. Explicit fore-fronting of diversity and gender analyses is a strategy within tobacco control for protecting such vulnerable groups. ${ }^{17}$

\section{MESSAGE ALTERNATIVES WORTH EXPLORING}

In the current study, all messages except the shame-based ad had previously been used in public campaigns, and Amonini et al acknowledged a potential novelty confound effect. Future investigation should compare multiple novel message themes; worth considering as an alternative are shame-free guilt appeals, which explicitly do not elicit shame.

Though Amonini et al did not find guilt to be as effective as shame, shame-free guilt messaging has been a powerful motivator in other contexts. A recent study promoting STD screening found that shame-free guilt appeals focusing on behavior (eg, "forgetful behavior") and the consequence of actions on others (eg, to elicit empathy) that identified specific coping strategies outperformed shame appeals that focused on intrinsic features of identity (eg, "an irresponsible person"). ${ }^{18}$ Since Amonini et al did not formally assess the impact of the ads on feelings of shame and guilt, we do not know whether the guilt ad utilised was 'shame-free.' Future messages assessed for elicitation of shame and guilt individually will be better equipped to help determine 
the risks and benefits of shame and/or guilt messaging.

In exploring novel public health approaches, studies such as Amonini et al's may move the field forward on the path to $100 \%$ smoke-free. Consistent with the Hippocratic oath of ethical practice in medicine, however, public health efforts above all must do no damage or harm. In particular, we should consider the effects on members of society under-represented in research efforts who are already socially isolated by socioeconomic circumstances or association with tobacco-stigmatised disorders. As tobacco use increasingly becomes denormalized, public health campaigns must not only attend to positive results, but also guard against harm in vulnerable groups. In particular, interventions that risk stigmatizing could backfire by exacerbating health disparities rather than reducing them.

Twitter Follow Cati Brown-Johnson at @catibrown

Funding This work was supported by the National Institute of Mental Health \#R01 MH083684, National Heart Lung and Blood Institute \#HL117736 and \#T32 HL007034, and the State of California Tobacco-Related Disease Research Program \#21BT-0018.

Competing interests JJP has served as an expert witness against the tobacco companies in lawsuits for which she has received fees for the work and has provided consultation to Pfizer, which makes medications for quitting smoking.

Provenance and peer review Commissioned; internally peer reviewed.

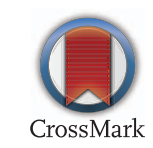

To cite Brown-Johnson CG, Prochaska JJ. Tob Control 2015:24:419-420.

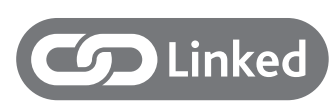

- http://dx.doi.org/10.1136/tobaccocontrol-2014051737

Tob Control 2015;24:419-420.

doi:10.1136/tobaccocontrol-2015-052233

\section{REFERENCES}

1 Amonini C, Pettigrew S, Clayforth C. The potential for shame as a message appeal in anti-smoking television advertisements. Tob Control 2015;24:436-41.

2 World Health Organization, Transport Accident Commission of Australia. 40 years of seat-beltsBelt up or Suffer the Pain. 2010. http://www.who. int/violence_injury_prevention/videos/australia_seat_ belts_40_years/en (accessed 10 Nov 2014).

3 Montague M, Borland R, Sinclair C. Slip! Slop! Slap! and SunSmart, 1980-2000: skin cancer control and 20 years of population-based campaigning. Health Educ Behav 2001;28:290-305.

4 Graham H. Smoking, stigma and social class. I Soc Policy 2012;41:83-99.

5 Mejia P, Dorfman L, Cheyne A, et al. The origins of personal responsibility rhetoric in news coverage of the tobacco industry. Am J Public Health 2014;104: 1048-51.

6 Halding A-G, Heggdal K, Wahl A. Experiences of self-blame and stigmatisation for self-infliction among individuals living with COPD. Scand I Caring Sci 2011;25:100-7.
7 Goffman E. Stigma: notes on the management of spoiled identity. Englewood Cliffs, NJ: Prentice-Hall Inc., 1963.

8 Brown-Johnson CG, Cataldo JK, Orozco N, et al. Validating the Internalized Stigma of Smoking Inventory (ISSI) with a seriously mentally ill population. UCSF Health Disparities Research Symposium VII. San Francisco, California, USA, 2013.

9 Chapple A, Ziebland S, McPherson A. Stigma, shame, and blame experienced by patients with lung cancer: qualitative study. BMJ 2004;328:1470-3.

10 Brown-Johnson C, Cataldo J, Orozco N, et al. Validity and reliability of the Internalized Stigma of Smoking Inventory: An exploration of shame, isolation, and discrimination in smokers with mental health diagnoses. Am J Addiction 2015. In press.

11 Stuber J, Galea S. Who conceals their smoking status from their health care provider? Nicotine Tob Res 2009;11:303-7.

$12 \mathrm{McCool}$ J, Hoek J, Edwards R, et al. Crossing the smoking divide for young adults: expressions of stigma and identity among smokers and nonsmokers Nicotine Tob Res 2012;15:552-6.

13 Thompson L, Pearce J, Barnett JR. Moralising geographies: stigma, smoking islands and responsible subjects. Area 2007;39:508-17.

14 Brown-Johnson CG, Brodsky JL, Cataldo JK. Lung cancer stigma, anxiety, depression, and quality of life. J Psychosoc Oncol 2014;32:59-73.

15 Cataldo JK, Brodsky JL. Lung cancer stigma, anxiety, depression and symptom severity. Oncology 2013;85:33-40.

16 Cataldo JK, Jahan TM, Pongquan VL. Lung cancer stigma, depression, and quality of life among ever and never smokers. Eur J Oncol Nurs 2012;16:264-9.

17 Amos A, Greaves L, Nichter M, et al. Women and tobacco: a call for including gender in tobacco control research, policy and practice. Tob Control 2012;21:236-43.

18 Boudewyns V, Turner MM, Paquin RS. Shame-free guilt appeals: testing the emotional and cognitive effects of shame and guilt appeals. Psychol Mark 2013;30:811-25. 